\title{
The Decarbonisation Challenge of Southeast Europe: A Case Study of Romania
}

As the EU moves towards committing to the decarbonisation of its economy to net-zero greenhouse gas (GHG) emissions in 2050, the Southeast European (SEE) member states are still struggling with dysfunctional energy mar-

Radu Dudău, Energy Policy Group, Bucharest; and University of Bucharest, Romania.

Mihnea Cătuţi, University of York, UK; and Centre for European Policy Studies, Brussels, Belgium. kets, blatantly inadequate long-term planning capabilities and an overwhelming dependency on fossil fuels. Combined, these factors represent significant impediments to the decarbonisation objectives in the region. The successful transition towards a low-carbon future in the EU relies on both the acknowledgement of the different starting points

(C) The Author(s) 2019. Open Access: This article is distributed under the terms of the Creative Commons Attribution 4.0 International License (http://creativecommons.org/licenses/by/4.0/), which permits unrestricted use, distribution, and reproduction in any medium, provided you give appropriate credit to the original author(s) and the source, provide a link to the Creative Commons license, and indicate if changes were made. 
of the SEE member states in the decarbonisation process and the resolution of the aforementioned problems.

This paper uses Romania as a case study to illustrate the SEE situation. First, this article briefly summarises the general European context and the framework through which member states will cooperate in the area of energy policy. Second, it showcases the energy and climate strategies of Romania. Third, it turns to some of the main barriers that the country is currently facing in reforming its energy markets. The final part of the article summarises the findings, while also suggesting some avenues that may be pursued to overcome the challenges of decarbonisation in SEE.

\section{SEE as part of the EU commitment to decarbonisation}

At the EU level, the target for GHG emission reductions has been set at $40 \%$ by 2030 compared to 1990 levels, in addition to a $32 \%$ target for renewable energy and a $32.5 \%$ target for improvement in energy efficiency. Meanwhile, in the European Council, member states are negotiating their commitment to net-zero emissions by 2050. The new president of the Commission, Ursula von der Leyen, has already set the European Green Deal as one of her top priorities, which aims at creating the tools necessary to reach this objective. As shown in the Commission's long-term strategy, ${ }^{1}$ which analysed potential decarbonisation pathways for 2050, such an endeavour requires not only an overhaul of national energy systems, but also wider economic and societal changes. Given the poor long-term planning capabilities and dysfunctional energy systems in SEE, such transformative actions will be difficult to implement.

With the 'Clean energy for all Europeans' package, the Regulation on the Governance of the Energy Union introduced a new cooperation framework between member states and the European Commission in the field of energy, which requires rigorous and standardised national energy and climate planning. A novelty of this package is that binding targets will only be set for the EU level. Under this new mechanism, each member state is required to produce an integrated National Energy and Climate Plan (NECP) for 2021-2030, which will be updated once by 30 June 2024. Member states must also release progress reports, with the first one due in 2023. The plans must be redacted in a binding template in which governments must outline the actions and strategies to be pursued for each dimension of the Energy Union. Moreover, member states will also be obliged to consider the long-term 2050

1 European Commission: A Clean Planet for all, COM (2018) 773 final, Brussels, 28 November 2018. perspective. The long-term strategies should be revised every five years and updated every ten years.

This framework provides both opportunities and challenges for the SEE countries. While the absence of binding national targets means that the new governance framework represents a 'softer' mechanism, it is not any less robust. ${ }^{2}$ The NECPs depend on national initiative and management of commitments, which can provide the needed flexibility for tailoring individual solutions. Moreover, by providing a binding template, the governance framework can trigger the development of rigorous national energy and climate planning, which has often been lacking in SEE. At the same time, however, this new system may also lead to tensions between this region (generally more reluctant to take on an aggressive decarbonisation timeline) and the Northern and Western member states. ${ }^{3}$ If these countries perceive their energy systems and security of supply to be vulnerable, they will likely adopt very defensive positions at the EU level to maintain strict control over their national energy mixes. ${ }^{4}$ This can lead to insufficiently ambitious NECPs, which may prove difficult to correct at a later stage. Hence, if the governance framework is to deliver on its objectives, the concerns of SEE member states cannot be ignored.

\section{The qualms of Romanian energy and climate planning}

Throughout the past decade, the necessity for strategic energy and climate planning in Romania followed the commitments associated with the EU accession. However, Bucharest has never had a full-fledged climate strategy. The only versions produced were sectorial, where the EU legislation demanded them (i.e. energy efficiency, GHG emissions reduction, buildings renovation). Ever since the EU accession, the strategic planning was linked to the GHG emission reduction targets of the EU and they were also integrated in energy sector planning. As explained in this section, the quality and relevance of the Romanian government's strategies have predominantly been questionable.

The first Romanian energy strategy was produced in 2007 for the period until 2020. This is still the only such document that has been adopted through a governmental decree, hence becoming official. However, it has a troublesome history. The World Wildlife Fund sued the govern-

2 S. Oberthür: Hard or Soft Governance? The EU's climate and energy policy framework for 2030, in: Politics and Governance, Vol. 7, No. 1, 2019, pp. 17-27.

3 M. Ringel, M. Knodt: The governance of the European Energy Union: Efficiency, effectiveness and acceptance of the Winter Package 2016, in: Energy Policy, Vol. 112, 2018, pp. 209-220.

4 M. Mišík: The influence of perception on preferences of new member states of the European Union: The case of energy policy, in: Comparative European Politics, Vol. 13, No. 2, 2015, pp. 198-221. 
ment for not having conducted a strategic environmental analysis (SEA) on the strategy, leading to its invalidation. After the SEA procedure, the government republished it in 2011 , but it was never again adopted officially by governmental decree. In any event, the proposed renewable energy target was $24 \%$ by 2020 . The energy efficiency goal was unambitious, based on the argument that the country was going through a restructuring of its energy and industrial systems, which would lead to energy savings anyway. The GHG emissions reduction target was also based on the assumption that emissions would decrease with the ceasing of energy-intensive industrial activity.

By 2014, it was clear that the strategy was outdated, therefore there was interest from both the industry and the government to produce a new energy strategy. The new document was published in December 2016 with the 2030 targets mirroring those agreed upon at the EU level by the European Council in 2014: 40\% GHG emissions reduction, $27 \%$ energy efficiency improvements and $27 \%$ for renewable energy sources. This was also the first strategy based on complex modelling, which was done using PRIMES, as well as real public dialogue.

That document, though, was subsequently modified and republished in October 2018 by the new government. Instead of relying on the aforementioned modelling and its scenarios, it was built around four predefined national interest projects: 1) reactors 3 and 4 at the Cernavodă Nuclear Power Station, 700MW each, 2) 1,000MW pumped storage hydro-power plant at Tarnița-Lăpuștești; 3) 600MW supercritical lignite power plant at Rovinari; and 4) hydropower energy complex Turnu Măgurele-Nicopole, on the Danube - vaguely defined. These are widely considered to be mere pride projects, with little prospect of turning into reality, albeit their respective odds are different. In fact, these projects have been around for years, even decades, and none of them is likely to overcome the underlying financial, environmental and social challenges. This approach has certainly undermined the strategy's relevance - not to mention the fact that, lacking a SEA procedure, it has not been officially adopted by governmental decree.

In November 2018, the Energy Ministry produced a draft NECP for 2021-2030. Largely committed to the strategic directions outlined in the energy strategy paper of October 2018, this draft has been criticised for lacking ambition and having a meager and often unrealistic analytic basis. ${ }^{5}$ As a matter of fact, unconvincing strategic plan-

5 Energy Policy Group: The Draft of the Romanian National EnergyClimate Plan 2021-2030, Policy Paper, December 2018, available at https://www.enpg.ro/wp-content/uploads/2018/12/NECP-RomaniaEPG-Analysis.pdf. ning has been an issue throughout the SEE. Negative reactions also emerged in the cases of Bulgaria, Croatia and Greece for having "failed thus far to adopt an ambitious integrated approach to energy and climate planning" and not projecting "significant reduction in coal use during the 2020-2030 period". ${ }^{6}$

The Commission issued recommendations for addressing part of the aforementioned issues: more ambitious renewable and energy efficiency targets; better reflection on the forward-looking objectives for market integration; increasing the competitiveness of wholesale and retail energy markets; and eliminating barriers to cross-border trade. ${ }^{7}$ It remains to be seen if the final version of the NECP will improve upon the previous draft that was published. ${ }^{8}$ Meanwhile, realistic steps have not been taken to address the causes for the general lack of vision and capacity of coherent long-term planning.

\section{Barriers to the reform of the Romanian energy markets}

For all its natural resources, well-balanced energy mix and low import dependence, the Romanian energy sector is presently in disarray, facing multiple challenges to its various subsystems: energy production, infrastructure and market mechanisms. Among the most important issues are the deficit of power generation, the crisis of the country's coal-fired power generation, the uncertain prospect of the gas finds in the Black Sea, a failing district heating in Bucharest and other major cities, and a strained business model of the electricity and gas distribution companies. The underlying causes of these problems are erratic policymaking, weak institutional capacity and poor longterm planning. This paper focuses on the first two of the enumerated problems as the more urgent ones.

\section{The deficit of power generation capacity}

As recently put by the president of ANRE, the national energy regulator, "[o]n paper, we have a lot of power generation capacity, over 24,000MW, of which only about $16,000 \mathrm{MW}$ are effectively available. The missing 8,000MW either do not exist physically or have not been available for a long time. We have identified more than 3,800MW missing, about which we will make a decision by the end of the year regarding the suspension of their

6 Agora Energiewende: Climate (Un)ambition in South East Europe: A critical Assessment of the Draft National Energy and Climate Plans, 162/06-A-2019/EN, 2019.

7 European Commission: Commission Recommendation on the draft integrated National Energy and Climate Plan of Romania covering the period 2021-2030, SWD (2019) 237 final, Brussels, 18 June 2019.

8 The definitive version of NECP must be submitted by the government to the Commission by 31 December 2019. 
license". ${ }^{9}$ In reality, the net power generation capacity is just under $11,000 \mathrm{MW}$ because large chunks of installed capacity have been either completely or largely unavailable. The reasons include repair works for scheduled or accidental shut-downs, plants in cold reserve that are only theoretically available, yet paid by the transmission system operator for technical system services, and units that work only sporadically for a very short period. Several times this year electricity production struggled to cover the load curve, even in intervals when the power demand was clearly under the yearly average. Thus, more than once in September 2019, both the daily and the hourly average prices on the day-ahead market were twice as high as on the price-coupled markets of Hungary, Slovakia and the Czech Republic with a peak of $€ 131 / \mathrm{MWh}$ on 18 September.

On that particular day, the average power demand was $6,703 \mathrm{MW}$, and the peak reached 7,697MW. About $11 \%$ of demand was covered by imports, with domestic power generation averaging 5,925MW. Domestically, lignite and hard coal covered $32 \%$, with the rest split among hydro $(25 \%)$, gas (15\%), nuclear (14\%), wind $(10 \%)$, solar (1\%) and biofuels (1\%)..$^{10}$ True, there was an unexpected shut-down of a 700MW nuclear unit in Cernavodă, which pushed the system close to its limits. However, in September and October, daily average load curve stayed mostly under 7,000MW, but even so, the electricity trade balance was mostly negative, with net imports typically at $10-20 \%$ of total consumption.

This is a clear trend reversal from the last few years, when the yearly net electricity trade used to see a surplus of ca. $10 \% .{ }^{11}$ This was mainly caused by a lack of investment in new power plants in Romania over several years. After the renewable energy boom of 2011-2013, the wind and solar investments gradually diminished until coming to a standstill in 2016, with no major project commissioned since. Regarding gas-fired power capacity, the latest significant capacity was OMV Petrom's Brazi plant in 2008. It is only at the end of 2020 that Romgaz, the state-controlled gas producer, intends to commission a new 400MW Combined Cycle Gas Turbine (CCGT) plant at Lernut. Meanwhile, Hidroelectrica has been facing difficulties in following its refurbishments plan, while the coal sector relies on

9 A. Mosoianu: Statul a lansat demontarea "ficțiunilor" din sistemul energetic românesc. ANRE a șters din statistici capacități de productie disponibile de peste 400 MW, in: Profit.ro, 9 October 2019.

10 Transelectrica: Operational report on the functioning of the National Energy System, October 31, 2019. Available at http://www.transelectrica.ro/documents/10179/25700/stare_sistem.pdf/abec253f-b200439a-9051-0ae3316c6386

11 According to Eurostat (2019), the net imports as percentage of electricity consumption in 2017 was $-5.9 \%$. an obsolete and polluting fleet of plants from the 1970s and 1980s.

This emergency situation is the effect of a regulatory environment dominated by unpredictable and often illadvised legal changes, as well as the absence of policy incentives for investment in power generation. Most consequentially, the notorious Governmental Emergency Ordinance (GEO) 114/2018 upended the entire energy industry: it froze the liberalisation of the gas market for three years by capping the price of domestically produced gas at merely Lei 68/MWh (€14.3/MWh) and imposed a $2 \%$ turnover tax on electricity and gas companies, including traders and suppliers. Some provisions were eased a few months later through GEO 19/2019, which restrained the gas price cap to the volumes purchased for household consumers, and narrowed the calculation basis for the $2 \%$ turnover tax while also creating further distortion by exempting the coal companies from the $2 \%$ tax.

While the dysfunction created by GEO 114/2018 was unprecedented, causing a dramatic fall in investors' confidence, other detrimental pieces of legislation had already been in place for several years. Thus, the Electricity and Gas Law No. 123/2012 precludes bilateral electricity contracts closed outside of the centralised market OPCOM to the extent that developers of wind and solar photovoltaic plants, in particular, have found it exceedingly difficult to ensure the bankability of their projects, in the absence of Power Purchasing Agreements (PPAs) to serve as collateral. Prohibiting PPAs has proven to be a major barrier to new renewable energy investments. Besides, the longterm policy planning has been driven by unrealistic pride projects, ${ }^{12}$ political interests and an anachronistic longterm view, unable to really factor in decarbonisation or commit to the EU-wide clean energy transition.

\section{The crisis of the coal-fired thermal power plants}

With about 4.5GW of installed capacity, the lignite and hard coal power plants account for more than one-third of Romania's average annual electricity production. The National Electricity Dispatcher uses 1,600-2,000MW of lignite power to cover the load curve. Out of the total yearly electricity production of ca. 60TWh, coal covers 25\%. Both the Oltenia Energy Complex (OEC), the lignite company, and the Hunedoara Energy Complex (HEC), the hard coal one, produce power and heat in cogeneration.

12 This is not to say that new nuclear power or pumped storage plants would not be needed in Romania, yet their concrete economics and financial arrangements, and certainly their environmental externalities, are to be duly considered against the background of today's green technology alternatives and policy targets. 
Over the past two years, the price hike of the $\mathrm{EU} \mathrm{CO}_{2}$ allowances (EUAs) has exacted an unbearable financial burden on the two state-owned coal companies. In September 2019, the EUA price was ca. €26, down from €29 in July - a level that had not been reached since just after the introduction of the ETS system. For the better part of the 2010s, the EUA price hovered between $€ 4$ and $€ 6$. To recollect: the recent price hike came on the heels of the ETS market reform, agreed upon in November 2017, with the introduction of the Market Stability Reserve in January 2019 , which resulted in a tightened balance of supply and demand.

This price trend of EUAs has greatly accelerated the demise of the coal-fired power generation sector in Romania. In 2018, OEC booked a loss of Lei 1.1 billion ( $€ 233$ million), mainly on account of the obligation to acquire $\mathrm{CO}_{2}$ allowances. It had to buy around 13 million EUAs by 1 May 2019 at a total cost of Lei 1.4 billion (€296 million), i.e. 40\% of downturn. To this purpose, the company took a loan of Lei 500 million ( $€ 106$ million) in April 2019. For its part, $\mathrm{HEC}$ is on the brink of insolvency. Its assets are presently under the sequester of the National Agency for Fiscal Administration or serve as collateral for the state guarantees given by the Finance Ministry. ${ }^{13}$

Indeed, continuing state aid to the coal sector is exactly what the government plans to do. On 24 September 2019 the Energy Ministry passed a memorandum in a government meeting with the following proposals meant to save the national lignite company from collapse:

- A merger between Hidroelectrica, the country's most profitable energy company, and OEC, which would basically come down to using most of Hidroelectrica profits to pay for OEC's $\mathrm{CO}_{2}$ costs;

- A governmental guarantee for a loan of Lei 1.2 billion (€250 million) for OEC to cover $\mathrm{CO}_{2}$ costs for 2019;

- Asking the Commission's approval for a state aid scheme for OEC of Lei 4.8 billion (€1 billion) for 20202025 , to be covered by all final consumers, dubbed an 'adequacy tax'.

13 The loan was taken in April 2015 with the European Commission's approval for state aid, following the EU rules for temporary rescue, and was supposed to be paid back in six months. The Energy Ministry submitted a restructuring plan on the company's long-term viability. However, HEC was unable to repay the loan, while the Commission concluded the restructuring plan could not ensure the company's long-term economic viability without continued state aid. In November 2018, the Commission found that HEC received around $€ 60$ million of incompatible state aid from Romania through four publicly financed loans. The state now needs to recover the illegal aid plus interest.
As the first and the third options are unlikely to come to fruition, the choice of a new state-guaranteed loan is the probable path, given that the OEC will require some form of state aid just to stay alive for reasons of security of supply. However, any state aid to the coal industry may only extend insofar as the energy security imbalance is still in place and sufficient alternative capacity is built. The market conditions of the coal industry are becoming untenable. Increasingly stringent EU regulations are creating a forbidding operational environment for the coal-fired plants. There is a limit of $550 \mathrm{~g} \mathrm{CO}_{2} / \mathrm{kWh}$ for power generation units admissible on the capacity markets as of 2025 , while the typical lignite-fired plant emits in excess of $1000 \mathrm{~g} \mathrm{CO}_{2} / \mathrm{kWh}$. New, restrictive BAT/BREF limits were placed on $\mathrm{NOx}, \mathrm{SO}_{2}$ and particulate emissions from Large Combustion Plants that must be met by the end of 2020 (but they are largely exceeded by the lignite plants in Romania). And on top of this, there is also the near full curtailment of EU finances for coal investment - except for the Modernisation Fund which, for Romania and Bulgaria alone, allows investment in the refurbishment of existing coal plants used for district heating.

Compelled to install power generation capacity as soon as possible, the government has planned investment in 930MW worth of CCGT capacity at three different OEC locations, to be commissioned in 2024 and 2026, as well as a 300MW gas plant at HEC's Mintia, also for 2024. These projects come on top of the progressing construction of a 430MW CCGT at Romgaz's Lernut facility, due to be commissioned in 2020, and a smaller-scale 73MW cogeneration gas unit at Rompetrol's Midia plant in Năvodari. Other projects may include a new 50MW gas turbine at CET Titan, in Bucharest, as well as other private projects for gas units. In total, one is likely to see up to $2,000 \mathrm{MW}$ of new gas-fired power generation in Romania by 2026.

Ironically, though, the government's change of heart about the future of the coal sector occurred just after the introduction of several pieces of legislation that have clearly disincentivised the domestic production of natural gas, thus rendering the country increasingly dependent on gas imports. The Offshore Law No. 256/2018 was very badly received by the Black Sea gas investors, while GEO 114/2018 delivered another severe blow to the oil and gas upstream segment. Meanwhile, ExxonMobil, the co-operator of the largest Black Sea gas find so far is reported to be seeking exit from its Neptun Deep project, which is likely to cause a fateful delay in the development of the country's offshore gas fields. This has taken place against the backdrop of a slow but steady trend of shrinking gas production in Romania, at a rate of $4-5 \%$ yearly. Thus, a heightened gas consumption over the next few years could only be met by growing gas imports. The resulting gas price exposure 
is likely to impact the profitability of those planned CCGT units, given also that they too will have to acquire expensive EUAs - albeit less than half per MWh than the lignite plants.

Getting a grasp on how the energy markets are going to evolve in the next ten years in light of such stringent climate and environmental regulations and factoring in the shifting technology costs is paramount for the country's ability to successfully decarbonise its economy while maintaining an adequate energy supply. The NECP ought to offer a path forward that includes both a short-term solution to the challenge of coal-fired power generation and a long-term trajectory towards decarbonisation. Solutions exist and the region has ample opportunities for the transition. For example, in Romania, only the former lignite and coal mining areas can offer land for solar power capacity estimated at over 60GW. ${ }^{14}$ It is therefore all the more important that the right regulations are put in place in order to incentivise timely and ample investment in renewables and in associated storage capacities.

\section{Conclusion}

Not only is Romania facing some crucial energy system problems, but the proposed solutions have often been improvised and incoherent. This also raises doubts about the

14 K. Bódis, I. Kougias, N.G. Taylor, A. Jäger-Waldau: Solar Photovoltaic Electricity Generation: A Lifeline for the European Coal Regions in Transition, in: Sustainability, Vol. 11, No. 3703, 2019. effectiveness of strategic planning aimed at implementing the energy transition to net-zero emissions by 2050 . While the empirical evidence analysed in this paper focused on Romania, similar problems have reverberated across the region.

Nonetheless, solutions exist. For example, while more than half of the electricity generation capacity in SEE relies on hard coal and lignite, a power system with a much higher deployment of renewable energy sources - as high as $50 \%$ by 2030 - has been shown to be realistic. ${ }^{15}$ No doubt, this will require drastic changes in the status quo. While the need for strategic planning is most evident, the energy transition will also rely on a mix of rigorous and ambitious policy design, availability and accessibility of diverse financial instruments for investments, as well as functional and transparent energy markets, accompanied by effective social protection for vulnerable energy consumers.

Under these circumstances, a sine qua non condition for a successful decarbonisation of the European economy is to understand the particularities of the member states in the SEE region, in order to address specific problems with targeted policy and financial interventions. This requires increased attention and cooperation from both EU institutions and other member states.

15 REKK Foundation: The Southeast European power system in 2030: Flexibility challenges and benefits from Regional integration, 154/03A-2019/EN/, 2019. 